\title{
Acardiac twin: a rare case report
}

\begin{abstract}
Twin reversed arterial perfusion sequence (TRAP), refers to a rare, unique complication of mono-chorionic twin pregnancy in which a twin with an absent or a nonfunctioning heart (acardiac twin) is perfused by its co-twin (pump twin) via placental arterial anastomoses. The acardiac twin usually has a poorly developed heart, upper body and head. The pump twin is at risk of heart failure and problems related to preterm birth. This case report presents an antenatally diagnosed mono-chorionic twin pregnancy, resulting in preterm delivery of a healthy, normal twin along with an acardiac co-twin.
\end{abstract}

Keywords: acardiac twin, mono-chorionic, twin reversal arterial perfusion, pump twin
Volume 5 Issue 5 - 2017

\section{Maasoumeh Mirzamoradi, Samaneh Esmaeili, Maasoumeh Saleh, Elham Pournajaf \\ MD, Department of Gynecology and Obstetrics, Mahdiyeh Hospital, Shahid Beheshti University of Medical Sciences, Iran}

Correspondence: Maasoumeh Saleh, Department of Gynecology and Obstetrics, Mahdiyeh Hospital, Shahid Beheshti University of Medical Sciences, Tehran, Iran, Tel/Fax +98-917$3210783,+98-21-22021000$

Email Salehmaasoumeh@yahoo.com

Received: July 29, 2017 | Published: August 10, 2017

\section{Introduction}

Multiple pregnancy accounts for $1.5 \%$ of all pregnancies, with approximate perinatal morbidity and mortality of $10 \% .{ }^{1}$ Multiple pregnancies is complicated by congenital malformations twice as often as with singletons. Some malformations, such as congenital twin and chorioangiopagus parasiticus due to twin reversed-arterialperfusion (TRAP) sequence, are unique to multiple pregnancy. ${ }^{2}$ TRAP sequence has historically been reported to occur in about 1 percent of mono-chorionic twin pregnancies and 1 in 35000 pregnancies. $^{3}$ In contemporary obstetrics, the incidence appears to be much higher, when factors such as the use of first trimester obstetrics ultrasound examination, which detects twin demises early in gestation, and assisted reproductive techniques, which have increased the incidence of twin including mono-chorionic twin, are accounted for.

A 2015 study estimated the incidence of acardiac twin is $2.6 \%$ of mono-chorionic twin pregnancies and 1 in 9500 to 11000 pregnancies. ${ }^{4}$ TRAP sequence chiefly results from abnormal placental vascular anastomoses with consequent increase in arterial pressure in 1 twin leading to reversal of blood flow in the other. As a result, the "pump" twin perfuses deoxygenated blood into the recipient (acardiac) twin. A spectrum of anomalies due to reduced formation of body tissue, as a consequence of severe hypoxia, results in acardiac-acephalus twin. Diagnosis of this syndrome was made with ultrasonography that is usually helpful from 11 weeks of gestation. ${ }^{5}$ At present there is a controversy regarding elective verses therapeutic treatment of reversed arterial perfusion sequence. ${ }^{6}$ Here we are presenting a case of TRAP sequence, which created a considerable management dilemma with respect to salvation of the pump twin.

\section{Case presentation}

A 28year-old Iranian woman primigravida, without any relevant medical history, was visited first at 12 weeks of gestation for an early pregnancy ultrasound. A twin pregnancy was noted with one amorphic embryo without heart activity. The nuchal thickness of surviving embryo was $1.6 \mathrm{~mm}$ and Nasal bone was present. The statue was diagnosed as di-amniotic twin pregnancy with early demise of one embryo. Follow-up was organized with routine structural ultrasound (anomaly scan) at 17 weeks of gestation, which no anomaly had been noted, but the size of the other embryo had been enlarged and the cardiac activity was undetectable in that. A reversal arterial flow was noted on a Doppler imaging study, coming from the apparently normal twin to the abnormal fetus and a diagnosis of TRAP sequence and acardiac twin made. It was decided to follow the pregnancy by further intensive monitoring of the surviving fetus and looking for eventual sign of cardiac decompensation, but the patient did not have any follow up till 33 weeks of gestation.

The patient was admitted at 33weeks of gestation and followed by ultrasound by a perinatal specialist and two $12 \mathrm{mg}$ doses of betamethasone were injected for lung maturity. At 34weeks of gestation, a live male fetus was noted, biometry was in accordance with 33 weeks of gestation and with an expected fetus weight of 2100 grams. Doppler investigations were normal. The biophysical profile of pump twin was reassuring. A large $(166 * 97 * 87 \mathrm{~mm})$ hypohetero-echoic mass (the amorphic fetus) without heart activity and with internal cystic calcification was seen (Figure 1). Some regions of the mass had vascularity. Due to suspected large volume of the acardiac twin, primary caesarean section was planned. At 35 weeks of gestation due to rupture of membrane, termination with caesarean section was performed. First the surviving fetus was delivered in cephalic presentation, a normal baby, weighing 2150grams, with APGAR score of 8 after 1 minute and 9 after 5 minutes (Figure 2). The umbilical artery PH was 7.46. After that, the acardiac twin, weighing 700 grams, was born. The acardiac twin did not have head and well defined limbs (Figures 3-7). Examination of the placenta demonstrated vascular connections between donor and receiver.

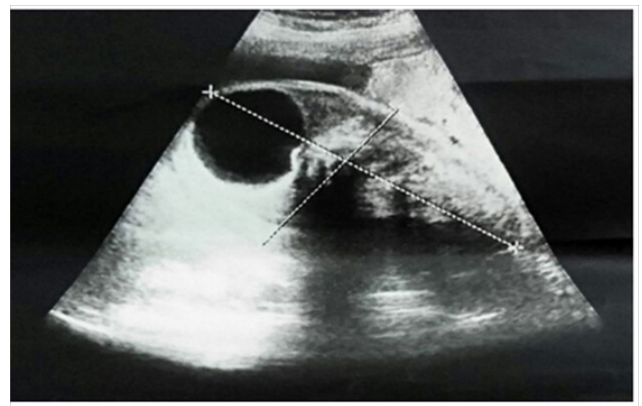

Figure I A large $(166 * 97 * 87 \mathrm{~mm})$ hypo-hetero-echoic mass (the amorphic fetus) without heart activity and with internal cystic calcification in ultrasound. 


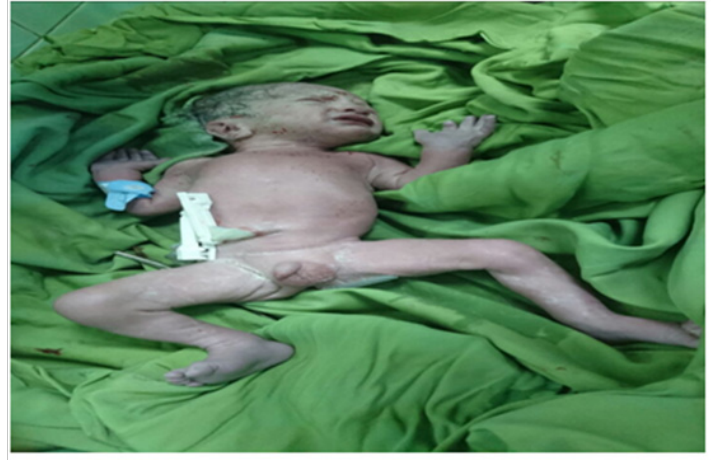

Figure 2 The normal baby.

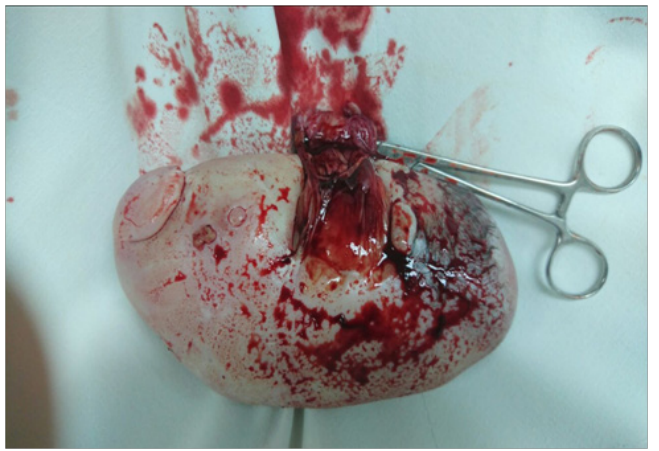

Figure 3 The acardiac twin without well defined head and limbs.

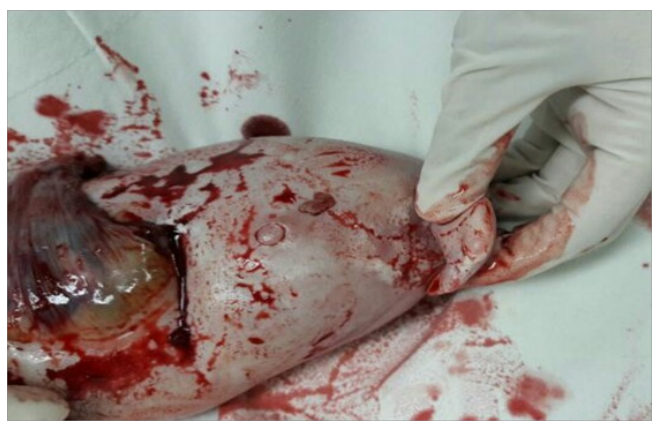

Figure 4 Acardiac twin.

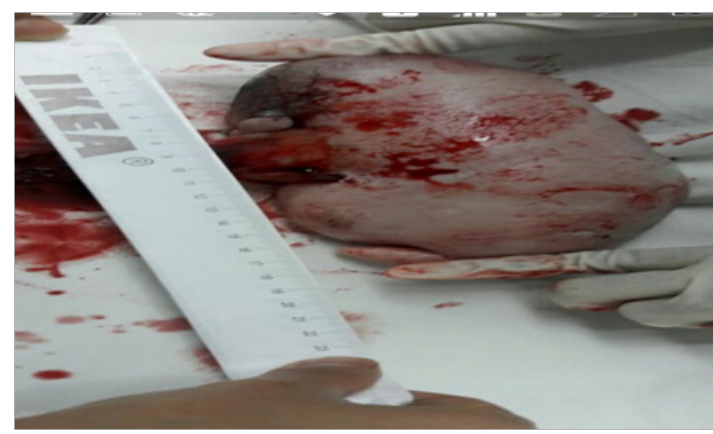

Figure 5 Acardiac twin.

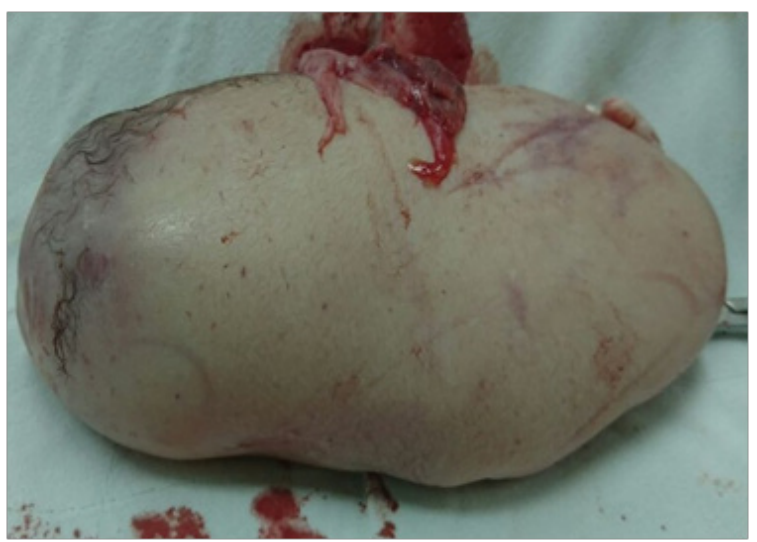

Figure 6 Acardiac twin.

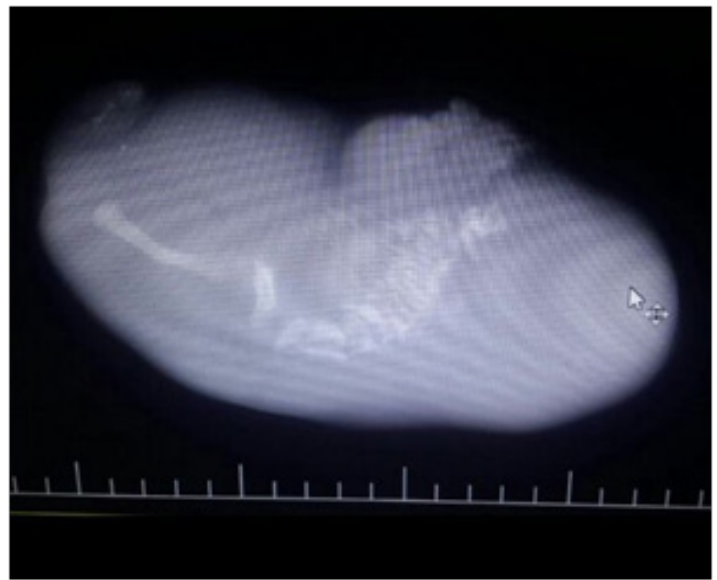

Figure 7 Acardiac twin imaging (X-Ray).

\section{Discussion}

The incidence of multifetal pregnancies has dramatically increased due to assisted reproductive technologies, although our case was in spontaneous conception. As a result, preterm labor, preterm premature rupture of the membrane, congenital anomalies and fetal losses are commonly encountered by obstetricians. Despite advances in diagnostic modalities and prenatal care, many times the complications associated with multifetal pregnancies may remain undiagnosed. Complications are more with mono-chorionic twin gestations due to placental sharing. ${ }^{7}$ The TRAP sequence, also known as acardiac twinning, is a malformation that occurs only in mono-chorionic pregnancies, with a frequency of about 1 per 35000 deliveries ${ }^{8-10}$ though nowadays; the incidence appears to be much higher, almost 2.6 percent of mono-chorionic twin pregnancies and 1 in 9500 to 11000 pregnancies. ${ }^{4}$ These extremely malformed fetuses have no heart at all (holoacardia) or only rudimentary cardiac tissue (pseudoacardia) in association with multiple other developmental abnormalities. ${ }^{11}$ Acardiac twins are sometimes classified by the degree of gross morphologic malformation: ${ }^{11-13}$

i. The first type is acardiac-acephalus, where no cephalic structures are present. Head and upper extremities are lacking. It is most common variety. 
ii. The second is acardiac-anceps, where some cranial structure and neural tissue or brain tissue is present. The body and extremities are also developed. It is highly developed form.

iii. The third is acardiac-acormus with cephalic structure, but no truncal structures are present. The umbilical cord is attached to the head. It is rarest form of the acardia.

iv. The fourth type is acardius-amorphous with no distinguishable cephalic or truncal structure. It is least developed and not recognizable as a human form with minimal development. This differs from teratomas only by its attachment to an umbilical cord. This is the type seen in the present case.

These classifications are used only as a descriptive tool because they have no clinical prognostic value. The acardiac twin receives all its blood supply from the pump twin through anastomotic channels; the term reversed perfusion is used to describe this condition, because blood enters the acephalic twin through umbilical artery and exit thorough umbilical vein which is apposite to the normal blood supply. The accardiac twin loses direct vascular connections with the placental villi and receiving its entire blood supply from the pump twin. Acardiac anomaly is more common in monozygotic female twins and mortality is $100 \% .{ }^{14}$ Patients with TRAP sequence always have a mono-chorionic placenta with vascular anastomoses that sustain the life of the acardiac twin..$^{9,15}$ More or less, large arterial anastomoses on the placental surface pump oxygen-poor blood from the donor twin to the acardiac twin, mean that the direction of blood flow in the umbilical cord of the acardiac is reversed; as compared to normal. Blood flow is from the acardiac twin back to the donor twin through veno-venous anastomosis. The acardiac twin can be considered a parasite with some tissue surviving due to the cardiac function of the donor. It is often noted that the lower half of the body is better developed as the oxygen poor blood from the umbilical artery and aorta first supplies the lower part and is almost completely depleted of oxygen when it reaches head, heart and arms.

Two theories exist as to the etiology of this condition:

i. One theory holds that the TRAP anomaly is caused by an abnormal twining event. ${ }^{11}$ Deep placental anastomoses in early embryogenesis cause malformation of the acardiac twin. The early pressure flow in one twin exceeds that of other, leading to the reversal of flow in the umbilical artery of the co-twin. ${ }^{12,16}$

ii. The alternative hypothesis is that the acardia is a primary defect in embryogenesis in one twin leads to failure of cardiac development. The normal twin then perfuses the acardiac twin via artery-artery anastomoses. The anastomoses are not responsible for the cardiac anomaly but are established as a result of it. ${ }^{12,16}$

The acardiac twin, otherwise destined to end in an early spontaneous abortion, continues to grow because of mono-chorionic vascular anastomoses to a normal co-twin. ${ }^{11}$ Antenatal diagnosis by ultrasound of an acardiac fetus coexisting with a normal co-twin is fairly straight forward. The only other entity in the differential diagnosis is an intrauterine fetal demise of one twin. However, continued growth of the abnormal presumed dead twin rules this out, as can demonstration of blood flow in the presumed dead twin by color Doppler. A retrograde pattern of fetal perfusion can be demonstrated to occur through the umbilical arteries.-The acardiac twin clearly has no chance of survival, but its presence is not innocuous for the normal pump twin. The pump twin, although structurally normal, is at increased risk for in utero-cardiac failure and mortality rates of $50 \%$ or higher have been reported. ${ }^{11}$ Unfavorable prognostic factors for the surviving twin, are a relatively high weight of the acardiac (particularly when this is more than $70 \%$ of the donor twin) (a quickly developing acardiac mass and some morphological features such as a developing head and upper limbs). A high resistance index in the umbilical artery of the acardiac twin is considered favorable. ${ }^{9,10,17,19}$

In the largest series of pregnancies complicated by TRAP sequence $(\mathrm{N}=49)$, Moore and Co workers reported $90 \%$ preterm delivery, $40 \%$ polyhydramnios and $30 \%$ cardiac failure of the normal pump twin, when the weight ratio was more than $70 \%$, compared with $70 \%$ preterm delivery, $30 \%$ polyhydramnios and $10 \%$ cardiac failure for the normal pump twin, when the weight ratio was less than $70 \% .{ }^{11}$ Management of patients with pregnancies complicated by TRAP is controversial. Expectant management with serial ultrasound surveillance, including fetal echocardiography, is reasonable in the absence of the poor prognostic features outlined previously. Delivery maybe indicated if signs of cardiac decompensation are noted at a viable gestational age. Maternal administration of digoxin and indomethacin have been attempted but with little evidence of benefit in the face of previable or peri-viable cardiac failure in the normal pump twin or if poor prognostic features are present. Another treatment option is interruption of the vascular communication between the twins. ${ }^{11}$ Historically, uterotomy and removal of the acardiac twin has been described. ${ }^{9}$

Later, endoscopic ligation of the umbilical artery and fetoscopic coagulation or ablation of the placental anastomosis have been described. ${ }^{9,10,17,19}$ Methods of vascular interruption have included ultrasound-guided injection of thrombogenic materials into the umbilical circulation of the acardiac twin, ligation of the umbilical cord of the acardiac twin under fetoscopic guidance and radio frequency cord ablation. ${ }^{2,20}$ Fetal survival after laser coagulation is around $70 \%$, mean gestational age at birth is 34 weeks and the failure rate is about $10 \%$. There is a high risk for preterm rupture of the membranes resulting in preterm or immature birth (up to $10 \%$ ). Intra-fetal ablation is technically easier and safer and more effective in comparison to more invasive techniques for umbilical artery occlusion. ${ }^{17}$ Intrafetal ablation has been described by alcohol injections, monopolar diathermy, ultrasound guided laser and radio frequency. ${ }^{17}$ The most recent development is percutaneous ablation of the acardiac through radiofrequency. This is an effective way to treat TRAP sequence but does not prevent eventful knotting of umbilical cords. ${ }^{15}$

Neonatal survival after this treatment is between $80 \%$ and $88 \%$ and the mean gestational age at delivery is 36 weeks. ${ }^{15,21}$ Recently, high intensity focused ultrasound (HIFU) has been described as a non-invasive treatment for occlusion of the blood flow in the acardiac twin. ${ }^{22}$ No comparative studies with HIFU exist. As pregnancy progresses, interventions become more and more difficult due to the enlarging diameter of the blood vessels. The optimal timing for treatment seems to be between 16 and 20 weeks gestational age. ${ }^{17}$ This necessitates early diagnosis and referral to a specialist center due to the low incidence of this specific complication in twin pregnancies. Early referral for detailed ultrasound in twin pregnancy should be advised to avoid missing the diagnosis, as demonstrated by this case. A non-invasive option is close observation with frequent ultrasound and termination of pregnancy as soon as the surviving twin shows signs of heart failure. ${ }^{9,10,18,21}$ 


\section{Conclusion}

This case demonstrate the importance of correct early diagnosis of acardiac twining to avoid later complications. Referring every twin pregnancy for a detailed early ultrasound to a specialized center, can avoid diagnosis and therapeutic difficulties later in the pregnancy. Prevention of preterm labor and diagnosing cardiac failure in the pump twin is very important. The average age at delivery is between 36 and 37 weeks. Invasive intervention is needed when the acardiac twin is more than $70 \%$ of the pump twin weighs; however, the prognosis appears to be poor. Intra-fetal ablation is the treatment of choice because it is simpler, safer and more effective than cord occlusion techniques. Conservative treatment is best suited for salvation of the pump twin when the acardiac twin is less than $70 \%$ of the pump twin weighs and there are no sign of impending heart failure. ${ }^{23}$

\section{Acknowledgements}

None.

\section{Conflict of interest}

The author declares no conflict of interest.

\section{References}

1. Hrbec Z, Robinette CD. The study of human twins in medical research. $N$ Engl J Med. 1984;310(7):435-441.

2. Rohilla M, Chopra S, Suri V, et al. Acardiac Acephalus Twin: A Report of 2 cases and Review of literature. Medscape J Med. 2008;10(8):200

3. Gillim DL, Hendricks CH. Holoacardius. Review of the literature and case report. Obstet Gynecol. 1953;2:647.

4. Van Gemert MJ, Van den Wijngaard JP, Vandenbussche FP. Twin reversed arterial Perfusion sequence is more common than generally accepted. Birth Defects Res A Clin Mol Teratol. 2015;103(7):641-643.

5. Sedigheh A, Leila P, Somayeh M, et al. Acardiac acephalus twin pregnancy with poor prenatal outcomes: a case report. Women's Health Bull; 2017.

6. Dubey S, Verma M, Goel P, et al. Twin reversed arterial perfusion: to treat or not. J Clin Diagn Res. 2017;11(1):QD05-D07.

7. Srivastava N, Bhatia T, Narshetty J, et al. Acardiac twin: a rare case report. International Journal of Infertility and Fetal Medicine. 2016;7(3):109110 .

8. James WH. A Note on the epidemiology of acardiac monsters. Teratology. 1977;16(2):211-216

9. Vandenbusseche F, Dprest JA, Klumper F, et al. Minimal invasive intrauterine chirurgische behandeling bij vier monochoriale tweelingzwangersc happenge compliceerd dor een acardiacus. Nedrlands Tijdschrift voor Geneeskunde. 2003;147:931-936.
10. Sullivan AE, Varner MW, Ball RH, et al. The management of acardiac twins: a conservative approach. Am J Obstet Gynecol. 2003;189(5):1310 1313.

11. Gabbe ST. Obstetrics: normal and problem pregnancies. 6th ed. USA: Sanders an imprint of Elsevier; 2012.

12. Van Allen MI, Smith DW, Shepard TH. Twin reversed arterial perfusion (TRAP) sequence: A study of 14 twin pregnancies with acardius. Semin Perinatol. 1983;7(4):285-293.

13. Prameela RC, Ranganath P, Nivedita S, et al. A rare case of acardiac twin: a case report. Int J Sci Stud. 2014;2(8):254-257.

14. Kiran P, Sangeeta A, Greetanjaly K. A rare case of acardiac acephalus twin pregnancy. J Obstet Gynecol India. 2010;60(1):75-76.

15. Lee H, Bebbington M, Crombleholme T. The North American fetal therapy network registry data on outcomes of radiofrequency ablation for twinreversal arterial perfusion sequence. Fetal Diagn Ther. 2013;33(4):224 229.

16. Athwal S, Millard K, Lakhoo K. Twin reversed arterial perfusion (TRAP) sequence in association with VACTERL: a case report. J Med Case Rep. 2010;22(4):411.

17. Tan T, Sepulveda W. Acardiac Twin: a systematic review of minimally invasive treatment modalities. Ultrasound Obstet Gynecol. 2003;22:409419.

18. Hartge D, Weichert J. Prenatal Diagnosis and Outcome of Multiple Pregnancies with Reversal Arterial Perfusion (TRAP-sequence). Archives of Gynecology and Obstetrics. 2012;286(1):81-88.

19. Prasad RH, Prasad TR, Kumar KD. TRAP-sequence-an interesting entity in twins. J Clin Imaging Sci. 2012;2:56.

20. Hartog M, Toolenar T, Jacquenyn Y. Late Presentation of Acardiac Twin: A case report and review of literature. Open J Obtet Gynecol. 2014;4(7):379382

21. Lewli I, Valencia C, Gonzalez E, et al. The outcome of twin reversed arterial perfusion sequence diagnosed in the first trimester. Am J Obstet Gynecol. 2010;203(3):1-4.

22. Okai T, Ichizuka K, Hasegawa J, et al. First Successful case of NonInvasive in utero treatment of TRAP-sequence by High Intensity focused ultrasound. Ultrasound Obstet Gynecol. 2013;42(1):112-114.

23. Weisz B, Peltz R, Chayen B, et al. Tailored management of twin reversed arterial perfusion (TRAP) sequence. Ultrasound Obstet Gynecol. 2004;23(5):451-455 